\title{
Comparação da remoção de turbidez e cor aparente em filtros lentos de areia com e sem adição de proteína imobilizada de Moringa oleifera
}

\section{Comparison of turbidity and apparent color removal in slow sand filters with and without Moringa oleifera immobilized protein}

\author{
Kamila Suemy Takassugui Satani ${ }^{1}$; Camila Clementina Arantes ${ }^{2}$; Tatiane Araújo de Jesus ${ }^{3}$ \\ ${ }^{1}$ Engenheira Ambiental e Urbana e Bacharel em Ciência e Tecnologia pela Universidade Federal do ABC, Santo André, \\ São Paulo, Brasil. Orcid: http://orcid.org/0000-0003-3324-5234. E-mail: kamilasuemy@hotmail.com \\ ${ }^{2}$ Professora do Curso de Engenharia Ambiental e Urbana do Centro de Engenharia, Modelagem e Ciências Sociais \\ Aplicadas, Universidade Federal do ABC, Santo André, São Paulo, Brasil. Orcid: http://orcid.org/0000-0002-2185-7084. \\ E-mail: camila.arantes@ufabc.edu.br \\ ${ }^{3}$ Professora do Programa de Pós-graduação em Ciência e Tecnologia Ambiental, Universidade Federal do ABC, Santo \\ André, São Paulo, Brasil. Orcid: http://orcid.org/0000-0002-5206-6584; E-mail: tatiane.jesus@ufabc.edu.br
}

RESUMO: O tratamento de água para consumo humano pode ser efetuado por diferentes métodos, com predomínio do tratamento por ciclo completo em regiões urbanizadas. A filtração lenta, tecnologia de baixo custo e facilidade operacional, é uma alternativa ao ciclo completo em comunidades rurais ou isoladas, desde que o manancial apresente os requisitos de qualidade necessários, em especial, turbidez < 10 UNT. Este trabalho teve como objetivo avaliar e comparar a remoção de cor aparente e turbidez de água sintética em três filtros lentos de areia distintos, com e sem proteína imobilizada de Moringa oleifera: (1) areia (FA); (2) extrato filtrado de $M$. oleifera aderido à areia (FA + EMOF); e (3) extrato peneirado de $M$. oleifera aderido à areia (FA + EMOP). A água sintética apresentou os seguintes valores médios: turbidez $(8,17 \pm 0,63 \mathrm{UNT})$ e cor aparente $(2,34 \pm 0,22 \mathrm{uC})$. A utilização da proteína imobilizada de $M$. oleifera aderida à areia resultou em menores valores de turbidez da água tratada $(<0,62$ UNT para FA + EMOP e $<0,3$ para FA + EMOF) quando comparado ao meio filtrante composto somente por areia, FA $(<1,23$ UNT). A ANOVA seguida de teste de Tukey denotou a existência de diferença significativa entre os resultados obtidos para a turbidez $(p=0,01382$ ), considerando o FA e demais filtros. Não foram observadas diferenças significativas em relação aos resultados obtidos para a cor aparente, entretanto, todos os valores obtidos foram iguais ou abaixo de 0,5 uC para a água tratada.

Palavras-chave: Cor aparente; Moringa oleifera; Proteína imobilizada; Tratamento de água; Turbidez.

ABSTRACT: The drinking water treatment can be carried out by different methods, whit a predominance of conventional water treatment in urbanized regions. The slow sand filtration is a low cost and operational easiness technology and an alternative to conventional water treatment in rural and isolates communities, since the water body has the required quality requirements, specially, turbidity < 10 NTU. This paper aimed to evaluate and to compare the removal of apparent color and turbidity of sintetic water by three different types of slow sand filtration, with and without Moringa oleifera immobilized protein: (1) sand (FA); (2) filtrate extract of M. oleifera adhered to sand (FA + EMOF); and (3) sifted extract of $M$. oleifera adhered to sand (FA + EMOP). The synthetic water presented the following mean values: turbidity (8.17 $\pm 0.63 \mathrm{NTU})$ and apparent color $(2.34 \pm 0.22 \mathrm{uC}$ ). The use of M. oleifera immobilized protein resulted in lower turbidity values of treated water $(<0.62$ NTU to FA + EMOP and $<0.3$ NTU to FA + EMOF) when compared to sand filter media, FA (<1.23 NTU). The ANOVA followed by Tukey test showed the existence of significant difference between the results obtained for turbidity $(p=0.01382)$, considering FA and other filters. No significant differences were observed in relation to the results obtained for apparent color; however, all obtained values were equal or below 0.5 uC for treated water.

Keywords: Apparent color; Moringa oleifera; Immobilized protein; Turbidity; Water treatment.

DOI: 10.18554/rbcti.v4i2.3721 
INTRODUÇÃO

As projeções realizadas pelo Instituto Brasileiro de Geografia e Estatística demonstram que a população brasileira aumentou em aproximadamente $7,8 \%$ nos últimos 19 anos. Tal estudo demonstra ainda que este aumento, tendo como base o ano de 2000, se aproximará de $20 \%$ em 2040 (BRASIL, 2018). O aumento populacional, além de elevar a demanda de água para o consumo humano, intensifica o desenvolvimento de atividades industriais e agrícolas para o atendimento das necessidades da população, o que afeta quanti e qualitativamente os recursos hídricos.

No aspecto da qualidade, pode-se afirmar que o uso dos corpos hídricos para diluição de águas residuárias é um dos fatores que mais contribuem para a degradação deste recurso em regiões urbanizadas. Já na zona rural, além da poluição decorrente do aporte de efluentes domésticos, a água pode ter sua qualidade deteriorada em consequência da não adoção de boas práticas agrícolas.

Quando destinada ao consumo humano, a água pode requerer tratamento para que sua qualidade seja compatível com o padrão de potabilidade previsto pela Portaria de Consolidação n. 5 do Ministério da Saúde (BRASIL, 2017). Apesar da existência de tecnologias aplicáveis na melhoria da qualidade da água, verifica-se que, de forma geral, estas são dirigidas para grandes volumes de água e grandes centros urbanos, locais nos quais predominam sistemas centralizados. Desta forma, nota-se a deficiência de tecnologias voltadas para pequenas comunidades, e, mais ainda, quando estas se apresentam em localização isolada.

Estas comunidades apresentam dispersão física e, muitas vezes, estão localizadas em áreas de difícil acesso, o que não só resulta em maior dificuldade e valores para implantação de um sistema de tratamento centralizado como também dificulta a identificação das demandas reais de cada comunidade. Sendo assim, se faz necessária a busca por alternativas simples e de baixo custo no tratamento da água para estas comunidades (LIMA, 2015).

Uma alternativa simplificada ao sistema convencional, com baixo custo e facilidade de operação, é a filtração lenta (PATERNIANI; CONCEIÇÃO, 2004). Tal tecnologia não requer a utilização de produtos químicos e de equipamentos sofisticados. Porém, tem-se a ressalva de que esta técnica é recomendada para águas com baixos valores de turbidez, em geral menor do que 10 UNT (DI BERNARDO; BRANDÃO; HELLER, 1999). Tal situação é observada em comunidades localizadas em áreas isoladas, rurais ou periféricas, que, em geral, apresentam melhor qualidade da água bruta, considerando a menor influência de atividades antrópicas próximas ou nos corpos d'água e melhor preservação ambiental do entorno, quando comparado aos meios urbanos.

Uma alternativa para o tratamento de água em comunidades rurais e isoladas são os coagulantes naturais, como a Moringa oleifera ( $M$. oleifera), árvore pertencente à família Moringaceae. Sua aplicação apoia-se no fato de que suas sementes são compostas por proteínas catiônicas, que apresentam efeito coagulante, podendo então ser usadas no processo de clarificação da água (FRANCO et al., 2017). Sánchez-Martín, Beltrán-Heredia e Peres (2012) apontam que o uso da M. oleifera como coagulante apresenta vantagens, tais como: simplificação do processo devido a não necessidade da correção do $\mathrm{pH}$ da água, uso de um produto natural com disponibilidade e acesso direto ao usuário, já que a $M$. oleifera apresenta alta viabilidade de cultivo, especialmente em países em desenvolvimento, os quais estão, em geral, situados em regiões com intensa irradiação solar. 
Saleem e Bachmann (2019), em estudo de revisão acerca da utilização de sementes de $M$. oleifera como coagulante, constataram que é viável a substituição de coagulantes à base de alumínio pelo coagulante natural. $\mathrm{O}$ uso de $M$. oleifera como coagulante na dose usual de $200 \mathrm{mg} \mathrm{L}^{-1}$ (aproximadamente 1 semente por litro de água a ser tratada) não acarreta em efeitos genotóxicos e mutagênicos, e, assim, seu uso não representa riscos à saúde humana (ROLIM et al., 2011). No entanto, Ghebermichael et al. (2005), alertam para o fato de que o elevado teor de matéria orgânica oriundo dos resíduos do extrato da semente de $M$. oleifera pode resultar na formação de trihalometanos quando a desinfecção é realizada por cloração.

Para minimizar tal efeito, o extrato aquoso pode ser filtrado antes da utilização, sendo reportados tratamentos do extrato antes do uso por meio de filtro de papel e malha de nylon (NDABIGENGESERE; NARASIAH; TALBOT; 1995), bem como membranas (MADRONA, 2010). Outra medida que pode reduzir a dosagem do coagulante e consequentemente a carga orgânica aportada na água é a extração do coagulante em solução salina, que de acordo com Okuda et al. (2001) potencializa a capacidade coagulante. Cabe destacar que o residual está relacionado com a eficiência do tratamento, já que parte da carga orgânica compõe os flocos formados.

Além disso, há estudos que sugerem a imobilização da proteína da $M$. oleifera e descarte do excesso de extrato aquoso antes do tratamento a fim de minimizar o residual de matéria orgânica. Como exemplo, Brota (2017) utilizou alginato de sódio, cloreto de sódio e cloreto de cálcio para a formação de esferas com o propósito de imobilizar a proteína da $M$. oleifera e, desse modo, evitar que o excedente de matéria orgânica seja adicionado ao processo. Xiong et al. (2018) e Jerri et al. (2012) constataram que a utilização de filtros de areia com proteína de $M$. oleifera possuem capacidade antimicrobiana e de remoção de turbidez da água efetivamente maiores quando comparados a filtros compostos apenas por areia. Xiong et al. (2018) consideram que este processo de tratamento de água pode ser aplicado em regiões e comunidades carentes dos países em desenvolvimento, dado que utiliza de materiais locais acessíveis e eficazes.

Tais estudos ainda são realizados em escala de bancada e focados na avaliação de parâmetros específicos, havendo necessidade de ampliação gradativa de escala para avaliação de viabilidade de implantação em maior escala, tratando volumes suficientes para atender residências unifamiliares e também avaliação de todos os parâmetros de qualidade estabelecidos pela Portaria de Consolidação n. 5 do Ministério da Saúde (BRASIL, 2017).

Nesse contexto, considerado que a imobilização da proteína no material filtrante apresenta viabilidade de uso em termos de melhoria da qualidade da água e que há necessidade de estudos ampliando a escala de operação, o presente trabalho teve como objetivo avaliar e comparar a remoção de turbidez e cor aparente em filtros lentos de areia com e sem adição de extrato de Moringa oleifera.

\section{MÉTODO}

A parte experimental deste trabalho foi desenvolvida no Laboratório de Águas Urbanas e Hidráulica Ambiental na Universidade Federal do ABC, no campus de Santo André. 
Água sintética

A água sintética foi produzida conforme metodologia adaptada a partir de Pritchard et al. (2010), que deve ser realizada em duas etapas: (1) Solução concentrada: adição de 2 gramas de bentonita natural para cada 1 litro de água da rede de abastecimento. Manter a mistura sob agitação até a completa homogeneização em agitador magnético. Manter a mistura em repouso por 30 minutos e coletar $750 \mathrm{~mL}$ do sobrenadante. (2) Diluir o sobrenadante coletado em 30 litros de água da rede de abastecimento. Considerando somente o parâmetro turbidez, a água utilizada representou características de corpos hídricos de águas doces classe 1 , onde a turbidez deve ser menor que 40 UNT, conforme Resolução n. 357 do CONAMA (BRASIL, 2005). A água sintética foi caracterizada com base nos parâmetros turbidez, cor aparente e pH, conforme metodologia descrita em APHA (2005).

\section{Preparo da areia}

Os ensaios foram realizados utilizando-se areia comercial (média) própria para filtros. Para tanto foi feito o peneiramento desta, de modo a obter as frações correspondentes de cada granulometria para posterior composição granulométrica, garantindo tamanho dos grãos variando entre 0,08 e $1,00 \mathrm{~mm}$, tamanho efetivo $\left(D_{10}\right)$ de $0,146 \mathrm{~mm}$ e coeficiente de desuniformidade (CD) igual a 3,26, características estas iguais ou muito próximas às indicadas para filtração lenta (DI BERNARDO; BRANDÃO; HELLER, 1999). A caracterização da areia foi feita seguindo recomendações da NBR 7217 (ABNT, 1987).

\section{Extrato de sementes de Moringa oleifera}

A coleta das sementes de $M$. oleifera foi realizada no campus da Universidade Estadual de Campinas, localizado em Campinas, SP. Em seguida, estas foram descascadas e mantidas em embalagem fechada hermeticamente para preservação de suas propriedades até o momento do uso.

As sementes foram processadas em liquidificador (Arno LN3711B1) por três minutos até a obtenção do extrato aquoso na proporção de $2 \%$ (Massa/volume), ou seja, para cada $1 \mathrm{~g}$ de pó de $M$. oleifera foram adicionados $50 \mathrm{~mL}$ de água destilada (JERRI et al., 2012).

A fim de avaliar a influência da presença de sólidos presentes no extrato aquoso, foram produzidos dois cenários: (1) filtração a vácuo, utilizando filtro qualitativo Whatman grau 1 de porosidade de $11 \mu \mathrm{m}$; (2) passagem por peneira metálica com abertura nominal de $300 \mu \mathrm{m}$.

\section{Material Filtrante}

Os materiais filtrantes foram preparados a partir da adição de cada um dos extratos (filtrado e peneirado), na concentração de $2 \%$, em volumes distintos de areia de modo que todo volume de areia fosse recoberto pelo extrato. Manteve-se a areia e o extrato em contato por período de 1 hora para que parte da fração sólida do extrato aderisse aos grãos de areia. Ao término desse processo, a mistura foi transferida para uma peneira com abertura de malha de $300 \mu \mathrm{m}$ com o objetivo de se retirar a fração líquida da mistura, 
mantendo-se somente areia e material proveniente das sementes de $M$. oleifera que tenha aderido aos grãos de areia.

\section{Montagem dos filtros e operação do sistema}

Foram confeccionadas 3 colunas de filtração utilizando tubos de PVC de $50 \mathrm{~mm}$ de diâmetro e $1 \mathrm{~m}$ de altura. A extremidade inferior do tubo foi vedada com uso de um CAP soldável e o meio filtrante foi sustentado por uma camada de manta geotêxtil não tecido posicionada sobre uma grelha. Um tubo de $20 \mathrm{~mm}$ foi conectado à extremidade inferior do filtro e utilizado como dreno para a saída da água filtrada. Após a montagem, foram adicionados $0,40 \mathrm{~m}$ dos materiais filtrantes preparados previamente em cada um dos filtros, sendo: (1) areia (FA); (2) areia com extrato de M. oleifera filtrado (FA + EMOF); e (3) areia com extrato de M. oleifera peneirado (FA + EMOP). Para evitar interferências de material que eventualmente pudesse se desprender da areia, antes de iniciar 0 tratamento, os registros foram abertos e as três colunas submetidas à lavagem contínua com água do sistema de abastecimento, por aproximadamente 15 horas, momento em que foi verificado que a água de entrada possuía a mesma turbidez que a de saída, atestando que o excesso de extrato e de resíduos presentes na areia haviam sido removidos.

A alimentação dos filtros foi feita a partir de um reservatório com misturador mecânico a fim de assegurar a homogeneização da água sintética. A operação dos filtros se deu de maneira contínua, com taxa de aplicação de $6,0 \mathrm{~m}^{3} \mathrm{~m}^{-2} \mathrm{dia}^{-1}$ (DI BERNARDO; BRANDÃO; HELLER, 1999) e nível de água variável. Os ensaios foram encerrados quando a lâmina de água acima do material filtrante atingiu 0,550 $\mathrm{m}$, sendo que a duração da carreira para cada um dos materiais filtrantes foi de 19 horas para o filtro de areia (FA) e 50 horas para os filtros de areia com extrato de $M$. oleifera filtrado (FA + EMOF) e de areia com extrato de $M$. oleifera peneirado (FA + EMOP). A Figura 1 ilustra o sistema montado e detalhe dos filtros.

Figura 1. (a) Representação esquemática do sistema de filtração montado. (b) Detalhe das colunas de filtração.

\begin{tabular}{|c|c|c|}
\hline & $(\mathrm{a})$ & $(\mathrm{b})$ \\
\hline & & \\
\hline
\end{tabular}


A coleta de amostras foi realizada a partir de tubulação posicionada na extremidade inferior dos filtros, três vezes por dia, bem como na entrada do sistema para caracterização da água sintética $(n=4)$. Visto que as carreiras de filtração tiveram durações distintas, o número de amostras coletadas para cada filtro também variou, totalizando três amostras para o FA, e seis amostras para FA + EMOF, bem como para o $F A+E M O P$.

\section{Parâmetros avaliados}

A turbidez foi determinada por meio de turbidímetro (Policontrol, AP 2000). A cor aparente foi determinada por fotocolorímetro (Policontrol, Aquacolor). Já o pH foi determinado por pHmetro (Nova Insruments, modelo $\mathrm{NI}$ PHM). As análises foram realizadas conforme metodologias descritas em APHA (2005).

\section{Análise dos dados}

Para cada um dos tratamentos realizados, calcularam-se os valores máximos, mínimos, médias, medianas (percentil $50 \%)$ e quartis inferior $(25 \%)$ e superior $(75 \%)$ para turbidez, cor aparente e pH para plotagem de gráficos do tipo boxplot para os parâmetros citados. Utilizando as equações 1 e 2, calcularam-se também as reduções de turbidez e cor aparente, respectivamente, para cada uma das amostras. Além disto, para a comparação das médias obtidas entre os 3 tratamentos, realizou-se Análise de Variância (ANOVA) seguida de Teste de Tukey a 5\% de significância, utilizando o software Past (HAMMER, 2001). Considerou-se para análise estatística somente os dados antes do transpasse, constatado pelo aumento da turbidez.

Redução de turbidez $(\%)=\left(\frac{\text { turbidez água sintética-turbidez após filtração }}{\text { turbidez água sintética }}\right) \times 100$

Redução de cor aparente $(\%)=\left(\frac{\text { cor aparente água sintética-cor aparente após filtração }}{\text { cor aparente água sintética }}\right) \times 100$

\section{RESULTADOS E DISCUSSÃO}

\section{Caracterização da água sintética}

As características da água sintética utilizada na operação do sistema estão apresentadas na Tabela 1, onde se constata que a turbidez permaneceu sempre abaixo de 10 UNT.

Tabela 1. Características da água sintética $(n=4)$ utilizada nos ensaios.

\begin{tabular}{cccc}
\hline Parâmetro & Unidade & Média & Desvio padrão \\
\hline Cor aparente & $\mathrm{uC}^{(1)}$ & 2,34 & 0,22 \\
Turbidez & $\mathrm{UNT}^{(2)}$ & 8,17 & 0,63 \\
$\mathrm{pH}$ & - & 7,03 & 0,08 \\
\hline \multicolumn{2}{c}{${ }^{(1)}$ unidade de cor; ${ }^{(2)}$ Unidade } & Nefelométrica de Turbidez.
\end{tabular}




\section{Taxa de filtração}

Os valores para as taxas de filtração observados ao longo do experimento se mantiveram próximos ao estabelecido na metodologia, tendo sido constatados, na prática, valores médios de: $5,87 \mathrm{~m}^{3} \mathrm{~m}^{-2}$ dia $^{-1}$ para o filtro de areia (FA); $6,05 \mathrm{~m}^{3} \mathrm{~m}^{-2} \mathrm{dia}^{-1}$ filtro de areia com extrato de $M$. oleifera filtrado (FA + EMOF); e $5,87 \mathrm{~m}^{3} \mathrm{~m}^{-2} \mathrm{dia}^{-1}$ para o filtro de areia com extrato de $M$. oleifera peneirado (FA + EMOP).

\section{Reduções de turbidez e cor aparente}

A Figura 2 apresenta os resultados de turbidez e cor aparente na saída dos filtros ao longo dos experimentos. Notou-se tendência de reduções dos valores para os filtros de areia para ambos os parâmetros. Em relação aos demais filtros observaram-se valores de turbidez próximos a 0,5 UNT até 43 horas de operação. Após esse período, se acredita que tenha ocorrido o transpasse. Isso pode ter ocorrido devido ao aumento da carga hidráulica sobre os filtros. Já em relação à cor aparente para os demais filtros, apesar de os valores apresentarem variações, os resultados estiveram sempre abaixo ou iguais a $0,5 \mathrm{uC}$.

Figura 2. Valores de turbidez (UNT) e cor aparente (uC) na saída dos filtros ao longo dos experimentos.
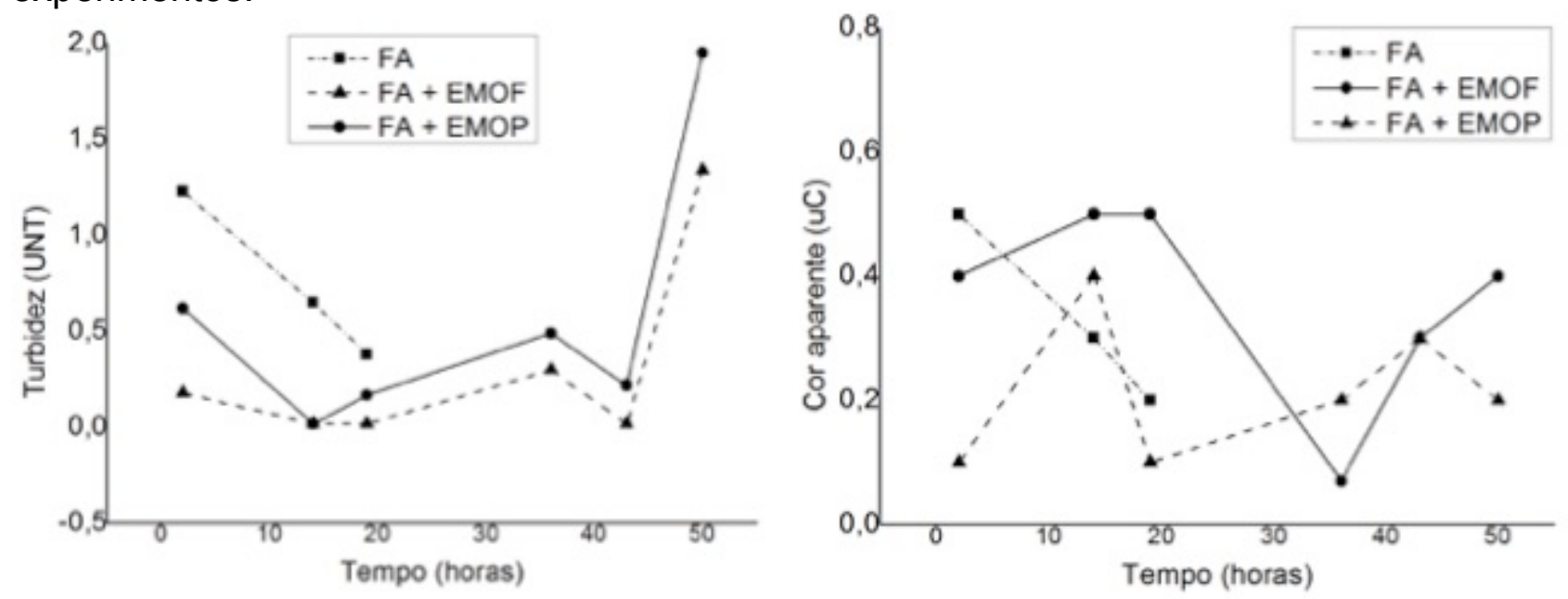

A Figura 3 apresenta as reduções (\%) de turbidez e cor aparente ao longo do tempo para os três tratamentos realizados. Notaram-se remoções superiores a $80 \%$ para a maioria das amostras analisadas. Eficiência similar foi constatada por Jerri et al. (2012), que obtiveram reduções de turbidez de $83 \%$ utilizando areia com proteína de $M$. oleifera aderida. Notou-se também que o filtro contendo apenas areia apresentou menor duração da carreira de filtração, a qual finalizou em 19 horas. 
Figura 3. Redução (\%) da turbidez (a) e da cor aparente (b) para os filtros: de areia (FA), com extrato de $M$. oleifera filtrado (FA + EMOF) e com extrato de $M$. oleifera peneirado $(\mathrm{FA}+\mathrm{EMOP})$.

(a)

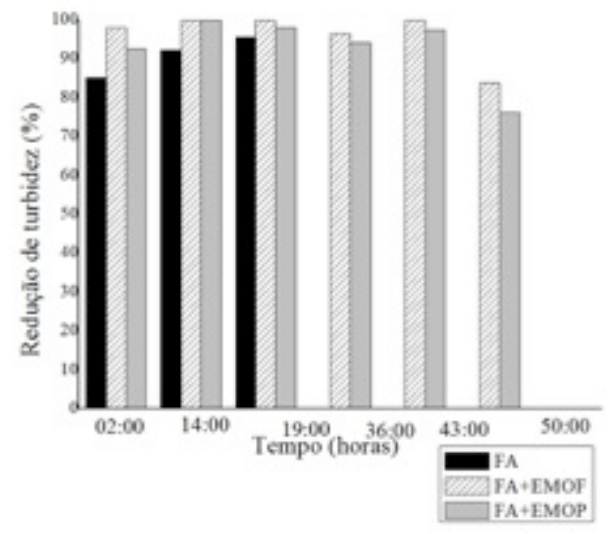

(b)

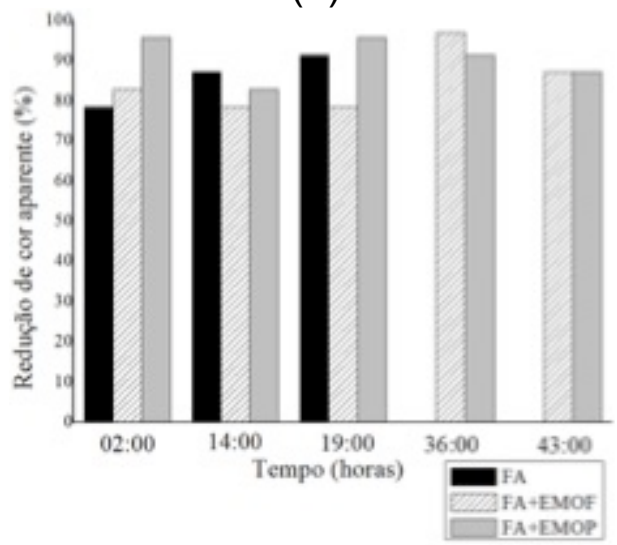

Os filtros com proteína imobilizada de $M$. oleifera apresentaram menores valores de turbidez ao longo da filtração quando comparados com os filtros de areia. A ANOVA seguida de Teste de Tukey indicou diferença significativa $(p=0,01382)$ entre esses resultados (Figura 4a). Em relação à cor aparente, os tratamentos não se diferenciaram estatisticamente (Figura $\mathbf{4 b}$ ).

Figura 4. Boxplot dos resultados de turbidez (UNT) e cor aparente (UC) para as saídas dos filtros de areia (FA) $(n=3)$, FA com extrato de $M$. oleifera filtrado (FA + EMOF) $(n=5)$ e FA com extrato de M. oleifera peneirado $(F A+E M O P)(n=5)$.

(a)

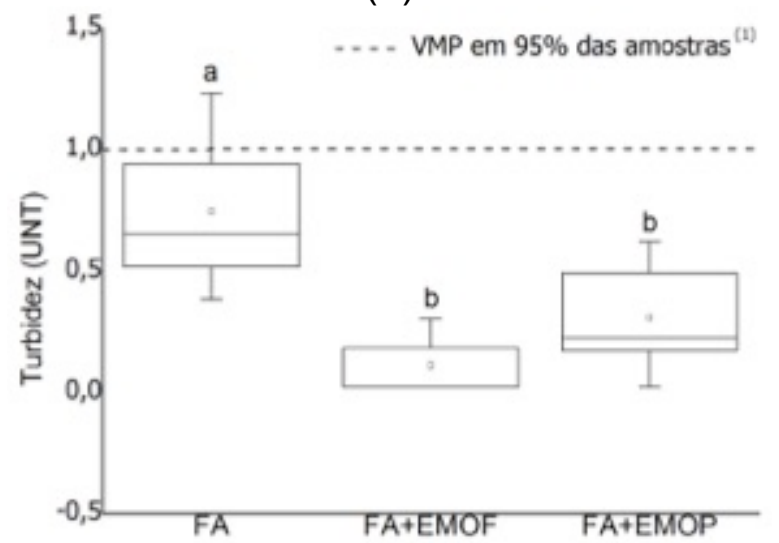

(b)

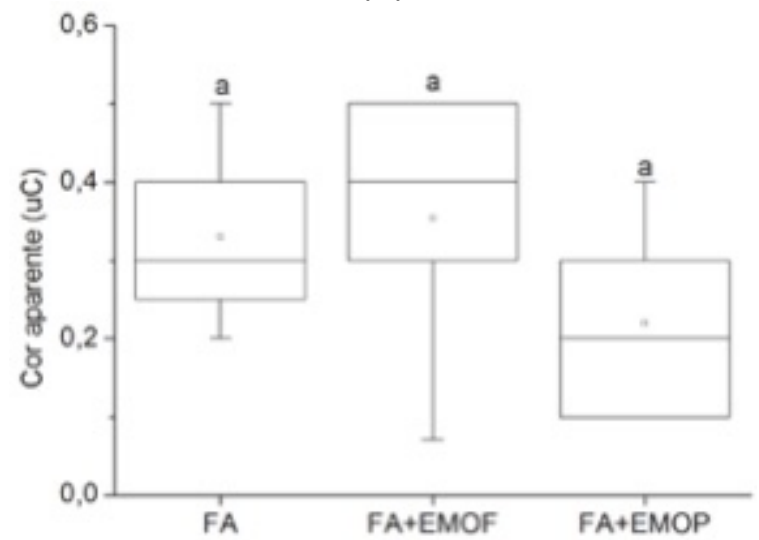

(1) VMP (Valor Máximo Permitido) para águas após tratamento por filtração lenta de acordo com a Portaria de Consolidação ${ }^{\circ} 5$ do Ministério da Saúde (BRASIL, 2017).

Letras iguais indicam que não há diferença significativa entre as médias com nível de significância de $5 \%$.

Estes resultados podem estar associados à presença de proteínas catiônicas da $M$. oleifera que podem ter favorecido a adesão de partículas presentes na água sintética ao meio filtrante em decorrência de forças superficiais (DI BERNARDO; PAZ, 2008), bem como devido a reduções na porosidade do material filtrante e consequente aumento da capacidade de retenção de sólidos (DI BERNARDO; BRANDÃO; HELLER; 1999). 
Comparando-se os valores obtidos com o estabelecido pela Portaria de Consolidação n. 5 do Ministério da Saúde (BRASIL, 2017) - turbidez de 1,0 UNT em 95\% das amostras, após a filtração lenta antecedendo a etapa de desinfecção -, tem-se que os valores obtidos satisfazem tal condição para os filtros com presença de extrato de sementes de $M$. oleifera. Para o filtro contendo apenas areia, a duração da carreira de filtração permitiu a coleta de apenas três amostras, estando uma delas acima de 1,0 UNT, o que não atenderia o estabelecido pela Portaria mencionada. A cor aparente, cujo valor médio para a água sintética foi de 2,34 $\pm 0,22 \mathrm{uC}$ e a Portaria citada estabelece como Valor Máximo Permitido $15 \mathrm{uC}$, permaneceu abaixo de 1,0 uC após os tratamentos, atendendo o padrão de potabilidade para este parâmetro.

pH

Os valores de $\mathrm{pH}$ se mantiveram na faixa de 6,94 a 7,15 para a água sintética; 6,92 a 9,04 para a saída do filtro de areia (FA); 6,46 a 7,22 para a saída FA + EMOF; e 6,75 a 7,21 para a saída do FA + EMOP. A ANOVA seguida do teste de Tukey, com nível de significância de $5 \%$, demonstrou que não há diferenças significativas entre as médias deste parâmetro comparando os três filtros.

\section{CONCLUSÕES}

A utilização da proteína imobilizada de $M$. oleifera aderida à areia resultou em menores valores de turbidez da água tratada $(<0,62$ UNT para FA + EMOP e $<0,3$ para $\mathrm{FA}+\mathrm{EMOF})$ quando comparado ao meio filtrante composto somente por areia, $\mathrm{FA}(<1,23$ UNT). A ANOVA seguida de teste de Tukey denotou a existência de diferença significativa entre os resultados obtidos para a turbidez. Não foram observadas diferenças significativas em relação aos resultados obtidos para a cor aparente, entretanto, todos os valores foram iguais ou abaixo de $0,5 \mathrm{uC}$ para a água tratada. Recomenda-se a realização de estudos que avaliem as caraterísticas do meio filtrante após a adição da proteína imobilizada de $M$. oleifera e os mecanismos envolvidos na retenção de impurezas nesse.

\section{REFERÊNCIAS}

ASSOCIAÇÃO BRASILEIRA DE NORMAS TÉCNICAS - ABNT. NBR 7217: Agregados Determinação de composição granulométrica. Rio de Janeiro: ABNT, 1987. 3 p.

AMERICAN PUBLIC HEALTH ASSOCIATION - APHA. Standard Methods for the

Examination of Water and Wastewater. 21. ed. Washington: American Public Health Association/American Water Works Association/Water Environment Federation, 2005. $1082 \mathrm{p}$.

BRASIL. Ministério da Saúde. Portaria de Consolidação n. 5, de 28 de setembro de 2017. Consolidação das normas sobre as ações e os serviços de saúde do Sistema Único de Saúde. Diário Oficial da República Federativa do Brasil. 926 p. 
BRASIL. Instituto Brasileiro de Geografia e Estatística. Tabela 2010-2060 - Projeção da População (revisão 2018). Disponível em: https://agenciadenoticias.ibge.gov.br/agenciadetalhe-de-midia.html?view=mediaibge\&catid=2103\&id=2188. Acesso em: 26 mar. 2019.

BRASIL. CONAMA - Conselho Nacional do Meio Ambiente. Resolução n. 357, de 17 de março de 2005. Dispõe sobre a classificação dos corpos de água e diretrizes ambientais para o seu enquadramento, bem como estabelece as condições e padrões de lançamento de efluentes, e dá outras providências. Disponível em:

http://www.mma.gov.br/port/conama/res/res05/res35705.pdf. Acesso em: 04 maio 2017.

BROTA, T. C. Imobilização de Moringa oleifera em alginato de sódio para o tratamento de água. Dissertação (Mestrado), Universidade Estadual de Campinas, Campinas, 2017. 110 p.

DI BERNARDO, L.; PAZ, L. P. S. Seleção de Tecnologias de Tratamento de Água: volume 2, 1. ed. São Carlos: LIDIBE LTDA, 2008. 1538 p.

DI BERNARDO, L.; BRANDÃO, C. C. S.; HELLER, L. Tratamento de Águas de Abastecimento por Filtração em Múltiplas Etapas. 1. ed. Rio de Janeiro: ABES/PROSAB, 1999. $121 \mathrm{p}$.

FRANCO, C. S.; BATISTA, M. D. A.; OLIVEIRA, L. F. C.; KOHN, G. P.; FIA, R. Coagulação com semente de Moringa oleifera preparada por diferentes métodos em águas com turbidez de 20 a 100 UNT. Engenharia Sanitária e Ambiental, v. 22, n. 4, p. 781-788, 2017.

GHEBREMICHAEL, K. A.; GUNARATNA, K. R.; HENRIKSSON, H.; BRUMER, H.; DALHAMMAR, G. A simple purification and activity assay of the coagulant protein from Moringa oleifera seed. Water Research, v. 39, p. 2338-2344, 2005.

HAMMER, Ø. Paleontological Museum, University of Oslo, Sars gate 1, 0562 Oslo, Norway David A. T. Harper. Geological Museum, Øster Voldgade 5-7, University of Copenhagen, DK-1350 Copen-hagen K, Denmark, 2001. 9 p.

JERRI, H. A.; ADOLFSEN, K. J.; MCCULLOUGH, L. R.; VELEGOL, D.; VELEGOL, S. B. Antimicrobial Sand via Adsorption of Cationic Moringa oleifera Protein. Langmuir, v. 28, n. 4, p. 2262-2268, 2012.

LIMA, N. M. Aplicação da Moringa oleifera no tratamento de água com turbidez. Dissertação (Mestrado), Universidade Católica de Pernambuco, Recife, 2015. 57 p.

MADRONA, G. S. Extração/purificação do composto ativo da semente da Moringa oleifera Lam e sua utilização no tratamento de água para consumo humano. Tese (Doutorado), Universidade Estadual de Maringá, Maringá, 2010, 197 p.

NDABIGENGESERE, A.; NARASIAH, K.S. \& TALBOT, B.G. Active agents and mechanism of coagulation of turbid waters using Moringa oleifera. Water Research, v. 29, n. 2, p. 703-710, 1995. 
OKUDA, T.; BAES, A. U.; NISHIJIMA, W.; OKADA, M. Coagulation mechanism of salt solution-extracted active component in Moringa oleifera seeds. Water Research, v. 35, n. 3, p. 830-834, 2001.

PATERNIANI, J. E. S.; CONCEIÇÃO, C. H. Z. Eficiência da pré-filtração lenta no tratamento de água para pequenas comunidades. Engenharia Ambiental: Pesquisa e Tecnologia, v. 1, n. 1, p. 17-24, 2004.

PRITCHARD, M.; CRAVEN, T.; MKANDWIRE, T.; EDMONDSON, A. S.; O'NEILL, J. G. A comparison between Moringa oleifera and chemical coagulants in the purification of drinking water - An alternative sustainable solution for developing countries. Physics and Chemistry of the Earth, v. 35, p. 798-805, 2010.

ROLIM, L. A.; MACÊDO, M. F.; SISENANDO, H. A.; NAPOLEÃO, T. H.;

FELZENSZWALB, I.; AIUB, C. A. Genotoxicity evaluation of Moringa oleifera seed extract and lectin. Journal of Food Science, v. 76, n. 2, p. T53-T58, 2011.

SALEEM, M.; BACHMANN, R. T. A contemporary review on plant-based coagulants for applications in water treatment. Journal of Industrial and Engineering Chemistry, v. 72, p. 281-297, 2019.

SÁNCHEZ-MARTÍN, J.; BELTRÁN-HEREDIA, J.; PERES, J. A. Improvement of the flocculation process in water treatment by using Moringa oleifera seeds extract. Brazilian Journal of Chemical Engineering, v. 29, n. 3, p. 495-502, 2012.

XIONG, B.; PIECHOWICZ, B.; WANG, Z.; MARINARO, R.; CLEMENT, E.; CARLIN, T.; ULIANA, A.; KUMAR, M. VELEGOL, S. Moringa oleifera f-sand filters for sustainable water purification. Environmental Science \& Technology Letters, v.5, n. 1, p. 38-42, 2018.

Recebido em: 09/05/2019

Aprovado em: 08/08/2019 